\title{
Author Correction: ISS observations offer insights into plant function
}

E. Natasha Stavros, David Schimel, Ryan Pavlick, Shawn Serbin, Abigail Swann, Laura Duncanson, Joshua B. Fisher, Fabian Fassnacht, Susan Ustin, Ralph Dubayah, Anna Schweiger and Paul Wennberg

Nature Ecology \& Evolution 1, 0194 (2017); published online 22 June 2017; corrected online 5 September 2017.

In the version of this Comment previously published, in Box 1, the spacing of the GEDI footprints should have read $60 \mathrm{~m}$ along the track, not $25 \mathrm{~m}$. Also the second affiliation for Susan Ustin was incorrect, she is only associated with the University of California, Davis. These errors have now been corrected. 